\title{
Structural robustness assessment of corroded buried pipes
}

\author{
A. U. Ebenuwa ${ }^{1}$, K. F. Tee ${ }^{1} \&$ Y. Zhang $^{2}$ \\ ${ }^{1}$ Department of Engineering Science, University of Greenwich, UK \\ ${ }^{2}$ School of Civil and Environmental Engineering, \\ Nanyang Technological University, Singapore
}

\begin{abstract}
This paper presents the study of the negative effects of corrosion on the robustness of buried pipeline based on deflection and bending strain failure modes. The fuzzy variable is used in the assessment to take into account the subjective character of the corrosion-induced failure. The approach gains its efficiency by scrutinizing the structural robustness at every membership level with respect to various degrees of imprecision. It is shown that the use of alpha-level discretization in the assessment of an entropy based robustness measure could produce credible results with better understanding of uncertainties associated with the failure of buried pipelines.
\end{abstract}

Keywords: robustness assessment, entropy measure, alpha-level discretization, failure modes, buried pipes, fuzzy.

\section{Introduction}

The analysis, assessment and maintenance of engineering structures involve uncertainties and imprecisions in both parameters and models [1-3]. Developing a reliable and efficient model for the analysis of uncertainties and imprecisions has attracted lots of attention from many researchers. In recent times, the use of fuzzy set for the uncertainty quantification in the engineering field and context is increasing. This covers a wide area of applications like image processing, decision making, cost analysis, data analysis, optimization and analysis of structural models [4-8]. In structural engineering, fuzzy sets are employed to model the imprecise uncertainties that are associated with the parameters in a structural system [9]. They have also been found as a useful analytical approach in other fields such as geotechnical engineering, mechanical engineering, hydrology and statistics [4, 
10]. Structural robustness can be described as the capacity of the structure to withstand the normal fluctuations of environmental conditions without noticeable effects on its serviceability $[11,12]$. Based on this, structural robustness assessment indicates a high degree of independence between the uncertainty of structural parameters and the associated uncertainty in structural response [13]. A structural system may be considered robust if it can survive some extreme conditions such as exceptional overloading, unforeseen events, and adverse environmental conditions without any substantial loss of safety and serviceability state of the structure. Also, the models and parameters used for the analysis of buried pipelines are often established on a combination of measurement, observation, experience, expert knowledge and code of practice, etc. [9]. Most of these data are limited or measured and estimated under poor quality condition. In order to address these problems, a robust assessment based on reliability and risk analysis of structures is needed. A brief review of some of these measures is given in Section 3.

Among the uncertainties mentioned above, corrosion is one of the most critical issues in the design of a pipeline which is associated with substantial economic loss [14-18]. The evaluation and estimation of corrosion is very difficult due to the lack of information and technological means. When dealing with imprecise information, it is advisable to employ an approach that can accommodate the vagueness and probabilistic nature of the uncertain parameters. For this reason, fuzzy sets are selected in this study for modelling the impact of corrosion on the deflection and bending strain of a buried pipe. The key reason for choosing fuzzy approach is because of its numerical capability in simulating the systems behavior which could incorporate the uncertainty and imprecision in the structural parameter as a set of values. Such a feature could help to characterize the uncertainties that could not be captured by a probabilistic approach. In this paper, robust assessment of buried pipelines is proposed based on fuzzy alpha-level set, interval analysis and evaluation of fuzziness using an analogy to Shannon's entropy as defined in [4, 10, 13], and [19]. According to the authors' understanding, there is no such work found in the literature on robust assessment of buried pipeline using fuzzy alpha-level sets. This paper focuses on the application of fuzzy alpha-level sets for the robust assessment of deflection and bending strain failure of a buried pipeline. The modelling of these failure modes is elucidated by means of robust assessment of buried pipelines under marine corrosion with reference to the data published by [20].

This paper is organized as follows. Section 2 presents an overview of fuzzy sets and fuzzy uncertainty. Section 3 presents a review of the literature on fuzzy robustness measure concepts and fuzzy sets theory. Section 4 provides the modelling of fuzzy corrosion uncertainty for the assessment of buried pipes. Section 5 explains the failure modes of buried pipe. Section 6 states the numerical example. Section 7 discusses the results, and significant findings and Section 8 provides the concluding remarks. 


\section{Fuzzy sets and fuzzy uncertainty}

Structural parameters whose uncertain characteristics have been identified as fuzziness can be treated on the basis of fuzzy set theory. A fuzzy set is a mathematical tool used in describing uncertain data whose information may be described as a set of intervals and their associated gradual assignment [21]. It offers a framework for analysing various types of information ranging from discrete data, continuous data, interval value data and linguistic knowledge.

In fuzzy uncertainty modelling, an interval value of a variable parameter $\mathrm{x}$ can be assessed with the aid of a membership value $\mu_{\mathrm{A}}(\mathrm{x})$. The membership value is between 0 and 1 . These values could be used to represent different practical meanings. For instance, the membership function can be used to represent degrees of uncertainty associated with the parameter. The fuzzy set model can be described with an uncertain preposition as in eqn. (1).

$$
\breve{\mathrm{A}}=\left\{\left(\mathrm{x}, \mu_{\mathrm{A}}(\mathrm{x})\right) \mid \mathrm{x} \in \mathbb{R}, 0 \leq \mu_{\mathrm{A}}(\mathrm{x}) \leq 1\right\}
$$

where $\breve{\mathrm{A}}$ is named the fuzzy set on the domain of $\mathrm{x}, \mu_{A}(x)$ is the membership function of the fuzzy sets. The membership function quantifies the level of membership of the elements $\mathrm{x}$ belonging to the fundamental set $\mathbb{R}$.

\section{1 $\alpha$-level discretization of a fuzzy set}

The concept of $\alpha$-level discretization is used to represent the fuzzy sets numerically with the aid of their $\alpha$-level values. Fuzzy sets can be discretized into a set of $\alpha$ levels with the support of $\alpha$-level cuts to the membership function values between 0 and 1. $\alpha$-level sets $\widetilde{\mathrm{A}}_{\mathrm{i}, \alpha_{k}}, \mathrm{i}=1, \ldots, \mathrm{n}$ form an $\mathrm{n}$-dimensional crisp subspace $\mathrm{X}_{\mathrm{ak}}$ of the $\mathrm{x}$-space [10].

For any $\alpha$-level set $\underline{A}_{\alpha_{k}}$ of a fuzzy set $\widetilde{A}$, it is defined as a crisp set associated with a selected real number $\alpha_{k} \in(0,1)[10,22]$.

$$
\underline{\mathrm{A}}_{\alpha_{\mathrm{k}}}=\left\{\underline{\mathrm{x}} \in \underline{\mathrm{X}} \mid \mu_{\mathrm{A}}(\underline{\mathrm{x}}) \geq \alpha_{\mathrm{k}}\right\}
$$

The following inclusion property will hold for $\alpha$-level sets belonging to the same fuzzy set.

$$
\underline{\mathrm{A}}_{\alpha_{\mathrm{k}}} \subseteq \underline{\mathrm{S}}_{\alpha_{\mathrm{i}}} \forall \alpha_{\mathrm{i}} ; \alpha_{\mathrm{k}}(0,1], \alpha_{\mathrm{i}} \leq \alpha_{\mathrm{k}}
$$

For a convex fuzzy set $\widetilde{\mathrm{A}}$, each $\alpha$-level set $\underline{\mathrm{A}}_{\alpha_{\mathrm{k}}}$ is a closed interval $\left[\mathrm{x}_{\alpha_{\mathrm{k}}, 1}, \mathrm{x}_{\alpha_{\mathrm{k}}, \mathrm{r}}\right]$ [19] with

$$
\begin{aligned}
& \mathrm{x}_{\alpha_{\mathrm{k}}, \mathrm{l}}=\min \left[\mathrm{x} \in \mathrm{X} \mid \mu_{\mathrm{A}}(\mathrm{x}) \geq \alpha_{\mathrm{k}}\right], \\
& \mathrm{x}_{\alpha_{\mathrm{k}}, \mathrm{r}}=\max \left[\mathrm{x} \in \mathrm{X} \mid \mu_{\mathrm{A}}(\mathrm{x}) \geq \alpha_{\mathrm{k}}\right] .
\end{aligned}
$$

The concept of $\alpha$-level discretization provides an efficient representation of fuzzy sets numerically. 


\section{Review of fuzzy robustness measure}

The idea of the robust structural system has been used in different engineering contexts and applications. An adequate robustness assessment of a structural system requires a measure of its uncertainty [7, 23]. However, there are no wellestablished and acceptable criteria for a consistent definition and determination of structural robustness [24]. In uncertainty theories, structural robustness measure is the assessment of the degree of independency between the changes in the structural input parameters and the associated fluctuations in structural response [7].

\subsection{Traditional concept of robustness measure}

In general, the traditional concept of structural robustness measure is defined as the comparison between the strength of the structural system with its non-damaged or intact state [25]. The elements of the structural member may have its own characteristics depending on different factors such as geo-environmental condition and loading patterns. According to [13] the reserve strength ratio of a structural system which is the ratio between the ultimate resistance of the intact state structure and the environmental design load is applied to measure the residual strength. This can be expressed mathematically as:

$$
\mathrm{RSR}=\frac{\text { ultimate resistance of intact structure }}{\text { design environmental load }}
$$

The corrosion of buried pipe occurs slowly as the structure continues to grow in age. Biondini et al. formulated a measure of time-variant structural robustness of concrete structures subjected to diffusive attacks from aggressive environmental agents with respect to the ultimate strength analysis [25]. From the formulated measure, the amount of local damage is first obtained at the member level by means of dimensionless damage index $0 \leq \delta \leq 1$ that is associated with the progressive deterioration of the material properties at a spatial point $\mathrm{x}$ and time t. The global measure of the damaged thickness $\Delta(\mathrm{t})$ at the cross-sectional level can be represented as follows.

$$
\begin{gathered}
\Delta(\mathrm{t})=[1-\omega(t)] \Delta_{c}(t)+\omega(t) \Delta_{S}(t) \\
\Delta_{c}(\mathrm{t})=\frac{\int_{A_{c}} W_{c}(x, t) \delta_{c}(x, t) d x}{\int_{A_{C}} W_{c}(x, t) d x} \\
\Delta_{S}(\mathrm{t})=\frac{\sum_{m} w_{s m}(x, t) \delta_{s m}(x, t) A_{s m}}{\sum_{m} w_{s m}(x, t) A_{s m}}
\end{gathered}
$$

where $\omega=\omega(t), w_{c}=w_{c}(x, t)$ and $w_{s m}=w_{s m} \omega(x, t)$ are the suitable weight functions. $A_{c}$ is the area of the concrete, and $A_{s m}$ is the area of the $m^{\text {th }}$ steel bar. The cross section formulation can be extended at the structural level by an integration over all the members of the system. 


\subsection{Entropy-based robustness measure}

The robustness assessment of the fuzzy uncertainty of structural parameters can be computed based on Shannon's entropy. Bothe suggested that the basic Shannon's entropy provided the needed information of the total amount of uncertainty contained in the declared character set [26]. Based on Shannon's approach, the uncertainty of a fuzzy variable can be quantified. The general entropy of a fuzzy set can be expressed as:

$$
H\left(\tilde{A}_{i}\right)=-K \cdot \int_{-\infty}^{+\infty} \quad \begin{gathered}
{[\mu(x) \cdot \ln (\mu(x))+} \\
(1-\mu(x)) \cdot \ln (1-\mu(x))] d x .
\end{gathered}
$$

where $\widetilde{\mathrm{A}}_{\mathrm{i}}$ is the fuzzy set which is a subset of the fundamental set X. This entropy measurement equation evaluates the 'steepness' of the membership function $\mu(\mathrm{x})$ of $\tilde{A}_{i} . \mathrm{H}=0$ for a crisp set and $\mathrm{H}$ is maximum if $\mu(\mathrm{x})=0.5$ [27].

Following the approach proposed by [13], entropy based robustness measure can be assessed at various membership levels with respect to the degree of imprecision in the fuzzy inputs and the associated imprecision in the fuzzy outputs. For instance, for a given fuzzy set $\tilde{A}$ at $\alpha$-level $\alpha_{k} \in(0,1]$, a new fuzzy set can be defined as the intersection of fuzzy set $\tilde{A}$ and the corresponding $\alpha$-level set $\tilde{A}_{\alpha_{k}}$. This is expressed in eqn (11).

$$
\widetilde{\mathrm{A}}_{\alpha_{\mathrm{k}}}=\widetilde{\mathrm{A}} \cap \mathrm{A}_{\alpha_{\mathrm{k}}}
$$

This approach is adapted in the entropy-based robustness assessment. The entropy based robustness assessment is now evaluated for each $\alpha$-levels as the ratio of the entropy of the fuzzy input to the entropy of the fuzzy structural response.

$$
\mathrm{R}\left(\alpha_{\mathrm{k}}\right)=\frac{\mathrm{H}\left(\tilde{\mathrm{x}}_{\alpha_{\mathrm{k}}}\right)}{\mathrm{H}\left(\tilde{\mathrm{z}}_{\alpha_{\mathrm{k}}}\right)}
$$

\section{Application to buried pipes}

Underground pipes are usually made of plastic, concrete, and metals. Most metal pipes can be made of steel, ductile iron and galvanized steel. Concrete pipes are made from materials composed of cement, water, sharp sand and stone. The damage of concrete pipe are often caused by biogenous sulphuric acid attack [27], while plastic pipes are not. According to [14] and [17], corrosion pit depth of a metal pipe can be modelled as a time function as in eqn (13).

$$
\mathrm{D}_{\mathrm{T}}=\mathrm{KT}^{\mathrm{n}}
$$

where $D_{T}$ is the pit depth and $\mathrm{T}$ is the time of exposure. $\mathrm{K}$ and $\mathrm{n}$ are the corrosion empirical constants which depend on the material of the pipe and the surrounding environment. To assess the amount of damage or reduction of the moment of inertia of pipe wall and the cross-sectional area of the pipe wall, the concept from [28] is used. For a flexible metal pipe, the moment of inertia and the cross sectional area of pipe wall per unit length can be expressed as in eqn (14) and eqn (15).

$$
\begin{aligned}
\begin{array}{l}
\text { Moment of inertia, } \\
\text { Cross-sectional area, }
\end{array} & \mathrm{I}=\left(\mathrm{t}-\mathrm{D}_{\mathrm{T}}\right)^{3} / 12 \\
\mathrm{~A}_{\mathrm{S}} & =\mathrm{t}-\mathrm{D}_{\mathrm{T}}
\end{aligned}
$$

where $t$ is the thickness of pipe wall and $D_{T}$ is the pit depth. 
In this practical example, the buried metal pipe is assumed to undergo gradual deterioration caused by uniform corrosion. The deterioration process can lead to different failure modes such as deflection and bending strain. To investigate the corrosion effect, the immersion corrosion data in [20] is used to model the corrosion pit depth. The membership function for the fuzzy corrosion depth at time $\mathrm{t}=4,8,12$ and 16 years are subjectively constructed according to the data points. The membership function is shown in Fig. 1.

The membership function is considered as linear where it connects the 5 percentile, the mean and the 95 percentile values in the experimental data. In this study, the uncertainty of corrosion pit depth is considered for the two failure modes of the buried pipeline. For simplicity, the analysis considers exposure periods of $4,8,12$, and 16 years.

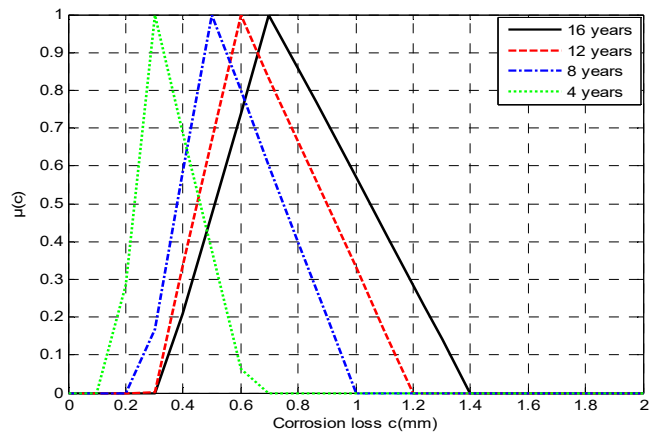

Figure 1: Membership functions developed from the immersion corrosion data of mild steel.

\section{Failure modes of buried pipelines}

It is crucial to identify the critical failure modes in order to avoid accidental economic loss and environmental pollution. In this analysis, corrosion failure modes of buried pipelines are considered. These include deflection and bending.

\subsection{Deflection}

Deflection is the movement of a structure or part of a structure from its original position. It is an important issue for engineers who may need to determine the maximum allowable load that a pipeline could take. The performance of a flexible pipe is assessed by measuring its deflection from its initial shape. This can be calculated from the ratio of the horizontal (or vertical) increased diameter to the original pipe diameter. The actual deflection, $\Delta y$ of a buried pipe can be calculated using (16) [29-31].

$$
\Delta_{\mathrm{y}}=\frac{\mathrm{K}_{\mathrm{b}}\left(\mathrm{D}_{\mathrm{L}} \mathrm{W}_{\mathrm{c}}+\mathrm{P}_{\mathrm{S}}\right) \mathrm{D}}{\left(\frac{8 \mathrm{EI}}{\mathrm{D}^{3}}+0.061 \mathrm{E}^{\prime}\right)}
$$

The load acting on the pipe are governed by the term $D_{L} W_{c}+P_{S}$ where $W_{c}$ is the soil load and $P_{S}$ is the live load. $E$ is the elastic modulus of pipe material, $D_{L}$ is the deflection lag factor, $K_{b}$ is the deflection coefficient, $D$ is the mean diameter 
which can be expressed as $D=D_{i}+2 C . D_{i}$ is the inner diameter and $C$ is the distance from inner diameter to the neutral axis. $E^{\prime}$ is the modulus of soil which can be expressed in (17).

$$
\mathrm{E}^{\prime}=\frac{\mathrm{K}^{\prime} \mathrm{E}_{\mathrm{S}}\left(1-\mathrm{V}_{\mathrm{s}}\right)}{\left(1+\mathrm{V}_{\mathrm{s}}\right)\left(1-2 \mathrm{~V}_{\mathrm{s}}\right)}
$$

where $v_{s}$ is the poison ratio, $K^{\prime}$ is the numerical value which depends on poison ratio and $E_{S}$ is the modulus of soil.

\subsection{Bending}

A pipe subjected to increasing pure bending will fail as a result of increased ovalisation of the cross-section and reduced slope in the stress-strain curve [32]. The bending of a buried pipeline depends on the surface loads acting on the pipe wall. The allowable bending stress $\sigma_{b}$ is the long term tensile strength of the pipe material and the allowable strain $\varepsilon_{b}$ of a flexible pipe is from $0.15 \%$ to $2 \%$ [33]. Actual bending stress $\sigma_{\mathrm{b}}$ and bending strain $\varepsilon_{b}$ can be calculated using eqn (18).

$$
\sigma_{\mathrm{b}}=2 \mathrm{D}_{\mathrm{f}} \mathrm{E} \Delta_{\mathrm{y}} \mathrm{y}_{\mathrm{o}} / \mathrm{D}^{2} \quad \varepsilon_{\mathrm{b}}=2 \mathrm{D}_{\mathrm{f}} \Delta_{\mathrm{y}} \mathrm{y}_{\mathrm{o}} / \mathrm{D}^{2}
$$

where $y_{o}$ is the distance from the centroid of pipe wall to the furthest surface of the pipe, $D_{f}$ is the shape factor and $\Delta_{y}$ is pipe deflection.

\section{Numerical example}

Consider the structural robustness assessment of a buried pipeline under the influence of corrosion-induced failure such deflection and bending strain. The main purpose of this numerical example is to demonstrate the efficiency and confidence level in using fuzzy-based method to assess the structural robustness of buried pipe. Tables 1 and 2 shows the random and non-random parameters employed for the analysis.

Table 1: $\quad$ Statistical properties of random variables.

\begin{tabular}{|l|c|c|c|}
\hline Material properties & Mean & $\begin{array}{c}\text { Coefficient of } \\
\text { variation }\end{array}$ & Standard deviation \\
\hline Elastic modulus of pipe, E & $213.74 \times 10^{6} \mathrm{kPa}$ (Normal) & 1.0 & $2.1374 \times 10^{6} \mathrm{kPa}$ \\
\hline Backfill soil modulus, $E_{S}$ & $10^{3} \mathrm{kPa}$ (Normal) & 5.0 & $50 \mathrm{kPa}$ \\
\hline Unit weight of soil, $\gamma_{S}$ & $18.0 \mathrm{kN} / \mathrm{m}^{3}$ (Normal) & 2.5 & $0.45 \mathrm{kN} / \mathrm{m}^{3}$ \\
\hline Wheel load(live load), $P_{S}$ & $80.0 \mathrm{kPa}$ (Normal) & 3.0 & $2.4 \mathrm{kPa}$ \\
\hline Thickness of pipe, $t$ & $0.021 \mathrm{~m}$ (Normal) & 1.0 & $0.00021 \mathrm{~m}$ \\
\hline Height of backfill, $H$ & $3.75 \mathrm{~m}$ (Normal) & 1.0 & $0.00375 \mathrm{~m}$ \\
\hline Deflection coefficient, $K_{b}$ & 0.11 (lognormal) & 1.0 & 0.0011 \\
\hline
\end{tabular}


Table 2: $\quad$ Material property constants and other parameters.

\begin{tabular}{|l|l|}
\hline Symbol description & Values \\
\hline Buoyancy factor, $\mathrm{R}_{\mathrm{w}}$ & 1.0 \\
\hline Capacity modification factor for pipe, $\varphi_{p}$ & $2.0 \mathrm{~m}$ \\
\hline Outside pipe diameter, $\mathrm{D}_{0}$ & $1.231 \mathrm{~m}$ \\
\hline Inside pipe diameter, $\mathrm{D}_{\mathrm{i}}$ & $1.189 \mathrm{~m}$ \\
\hline Deflection lag factor, $\mathrm{D}_{\mathrm{L}}$ & 1 \\
\hline Shape factor, $\mathrm{D}_{\mathrm{f}}$ & 4 \\
\hline Poison's ratio, $\mathrm{v}_{\mathrm{S}}$ & 0.3 \\
\hline$K^{\prime}$ & 1.5 \\
\hline Minimum tensile strength of pipe, $\mathrm{F}_{\mathrm{y}}$ & $450 \mathrm{MPa}$ \\
\hline
\end{tabular}

\section{Results and discussion}

The specified fuzzy variable in Fig. 1 is utilized in the robustness assessment of a buried pipe for modeling the corrosion pit depth. The entropy values associated with the $\alpha$-level of the fuzzy results for different failure modes, normalized by $H(p)$ are shown in Fig 2 for an exposure period of 16 years. The result clearly indicates a reduction of imprecision in the fuzzy input which led to a reduction of imprecision in the fuzzy output. It was observed from the results that the imprecision associated with the input parameter has a trade-off in reducing the imprecision associated with the computed output for the two failure conditions.

The deflection results for 16 and 12 years in Fig. 3 show a close robustness behavior when $\alpha_{\mathrm{k}} \leq 0.2$. However, as the alpha level increases, the deflection results for 12 years continue to show a greater value than the case of 16 years. For the others cases ( 4 years and 8 years), the robustness measure is quite distinctive. For 4 years and 8 years at $\alpha_{k} \geq 0.8$, there is a sudden increase in the robustness value. This means that the pipe deflection is more robust for $\alpha_{k} \geq 0.8$ compared to $\alpha_{\mathrm{k}} \leq 0.8$. The robustness assessment of deflection at that level may require collecting additional information about the corrosion process. Besides, as the number of service years increases, the robustness measure tends to normalize and shows a similar trend indicating ductility nature of the pipe material.

For the four different years that are considered, the result indicates that the values of the robustness measure continue to decrease as the number of service years increases. For example, the robustness values of deflection at $\alpha_{1}$ to $\alpha_{11}$ decrease from $1139,1254,1452,1184,1212,1790,1207,745$ and 981 in 4 years to $225,268,240,228,237,279,292,347$ and 351 in 16 years. This means that the level of uncertainty and the impact of corrosion can potentially reduce the residual strength of the pipe structure. Similarly, for exposure of 4 years and 16 years, the failure modes of pipe for deflection and bending strain shows close behavior as in Figs 4 and 5. 


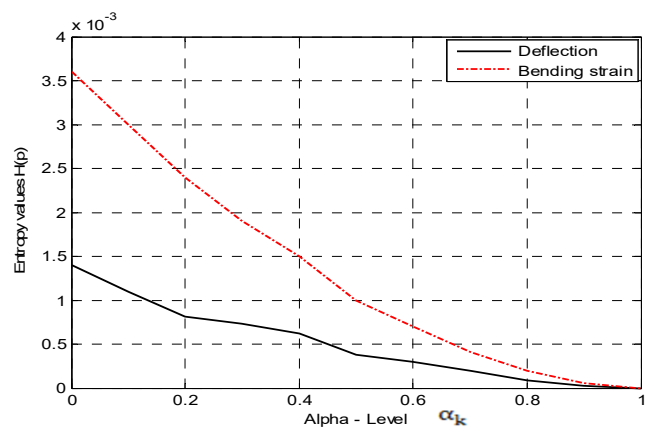

Figure 2: $\quad$ Entropy state for both failure modes after 16 years.

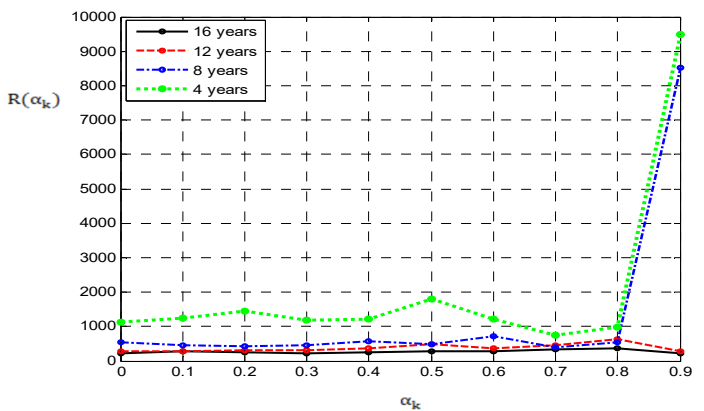

Figure 3: Robustness assessment of buried pipe due to deflection.

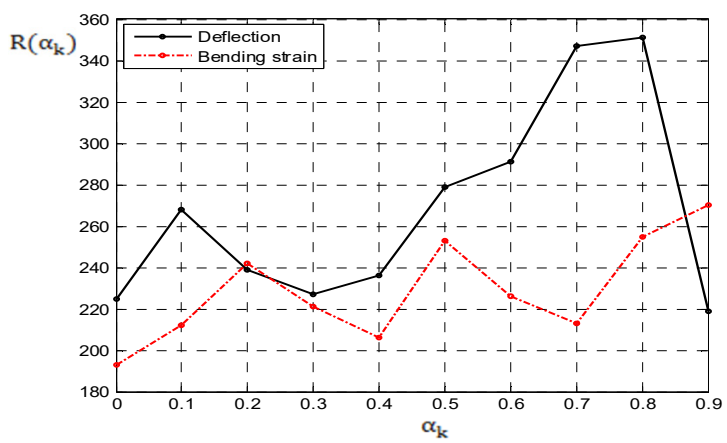

Figure 4: Robustness assessment of buried pipe for 16 years. 


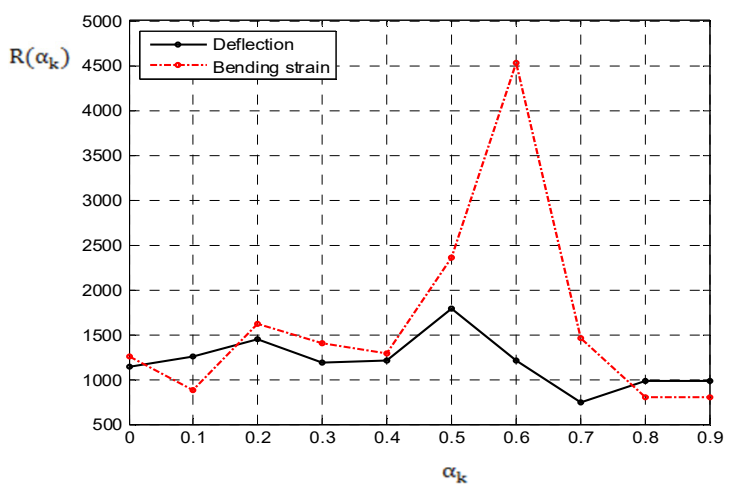

Figure 5: Robustness assessment of buried pipe for 4 years.

\section{Conclusions}

This paper presents a fuzzy based robustness assessment of corroded, buried pipes. The fuzzy model is used to quantify the imprecise information regarding the corrosion effects at different periods of time. The evaluation is conducted for various degrees of uncertainties in the considered corrosion pit depth of a buried pipe. The results show that the fuzzy based robustness measure can provide a comprehensive understanding of the influence of corrosion uncertainty to the investigated failure modes. The fuzzy modelling considers different degrees of indeterminacy of the input information. This can lead to optimal engineering decisions where a level of accuracy is required. In contrast to other approaches, the fuzzy approach has proven to be more robust and conservative in evaluating the performance of buried pipes.

\section{References}

[1] Tee, K.F., Khan, L.R. \& Coolen-Maturi, T., Application of receiver operating characteristic curve for pipeline reliability analysis. Journal of Risk and Reliability, Proceedings of the Institution of Mechanical Engineers, Part O, 229(3), pp. 181-192, 2015.

[2] Fang, Y., Chen J. \& Tee, K.F., Analysis of structural dynamic reliability based on the probability density evolution method. Structural Engineering and Mechanics, 45(2), pp. 201-209, 2013.

[3] Khan, L.R., Tee, K.F. \& Alani, A.M., Reliability-based management of underground pipeline network using genetic algorithm, Proc. of the $11^{\text {th }}$ International Probabilistic Workshop, Brno, Czech Republic, November 68, pp. 159-170, 2013.

[4] Ross, T.J., Fuzzy logic with engineering applications, Second edition. Wiley, 2004. 
[5] Dubios, D. \& Prade, H., Fuzzy sets and systems: theory and applications, Academic Press, New York, 1980.

[6] Ke, H. \& Ma, J., Modelling project time-cost trade-off in fuzzy random environment, Applied Soft Computing, 19, pp. 80-85, 2014.

[7] Moller, B. \& Beer, M., Engineering computation under uncertainty capabilities of non-traditional models, Computer and Structures, 86(10), pp. 1024-1041, 2008

[8] Fang, Y., Xiong, J. \& Tee, K.F., Time-variant structural fuzzy reliability analysis under stochastic loads applied several times, Structural Engineering and Mechanics, 55(3), pp. 525-534, 2015.

[9] Beer, M., Ferson, S. \& Kreinovich, V., Imprecise probabilities in engineering analyses, Mechanical Systems and Signal Processing, 37(1-2), pp. 4-29, 2013.

[10] Moller, B. \& Beer, M., Fuzzy Randomness - uncertainty in civil engineering and computational mechanics, New York, Springer-Verlag, Berlin Heidelberg, 2004.

[11] Tee, K.F., Khan, L.R., Chen, H.P. \& Alani, A.M., Reliability based life cycle cost optimization for underground pipeline networks, Tunneling and Underground Space Technology, 43, pp. 32-40, 2014.

[12] Fang, Y., Wen, L. \& Tee, K.F., Reliability analysis of repairable k-out-n system from time response under several times stochastic shocks, Smart Structures and Systems, 14(4), pp. 559-567, 2014.

[13] Zhang, M., Beer, M., Koh, C.G. \& Jensen, H., Nuanced robustness analysis with limited information, ASCE-ASME Journal of Risk and Uncertainty in Engineering Systems, Part A: Civil Engineering, B4015001, 2015.

[14] Ahammed, M. \& Melchers, R.E., Reliability of pipelines subject to corrosion, Journal of Transportation Engineering, ASCE, 120(6), pp. 9891002, 1994.

[15] Rajabipour, A. \& Melchers, R.E., A numerical study of damage caused by combined pitting corrosion and axial stress in steel pipes, Corrosion Science, 76, pp. 292-301, 2013.

[16] Melchers, R.E., Recent progress in the modelling of corrosion of structural steel immersed in seawaters, Journal of Infrastructural Systems, 12(3), pp. 154-162, 2006.

[17] Sadiq, R., Rajani, B. \& Kleiner, Y., Probabilistic risk analysis of corrosion associated failures in cast iron water mains, Reliability Engineering and System Safety, 86(1), pp. 1-10, 2004.

[18] Khan, L.R. \& Tee, K.F. Quantification and comparison of carbon emissions for flexible underground pipelines, Canadian Journal of Civil Engineering, 42(10), pp. 728-736, 2015.

[19] Beer, M. \& Liebscher, M., Designing robust structures - A nonlinear simulation based approach, Computers and Structures, 86(10), pp. 1102$1122,2008$.

[20] Melchers, R.E., Probabilistic models for corrosion in structural reliability assessment. Part 1: Empirical models, J. Offshore Mech. Arctic Eng., 125, pp. 264-271, 2003. 
[21] Zadeh, L.A., Fuzzy sets, Information and Control, 8, pp. 338-353, 1965.

[22] Moller, B., Graf, W. \& Beer, M., Safety assessment of structures in view of fuzzy randomness, Computer and Structures, 81(15), pp. 1567-1582, 2003.

[23] Hanss, M. \& Turrin, S., A fuzzy-based approach to comprehensive modelling and analysis of systems with epistemic uncertainties, Structural Safety, 32(6), pp. 433-441, 2010.

[24] Starossek, U. \& Haberland, M., Approaches to measures of structural robustness, 4th International Conference on Bridge Maintenance, Safety and Management, 2008.

[25] Biondini, F., Frangopol, D.M. \& Restelli, S., On structural robustness, redundancy and static indeterminacy, ASCE Structures Congress, Vancouver, B.C., Canada, April 24-26, 2008.

[26] Bothe, H.H., Fuzzy logic, New York, Springer, Berlin Heidelberg, 1993.

[27] Beer, M. \& Liebscher, M., Designing robust structures - A nonlinear simulation based approach, Computers and Structures, 86(10), pp. 1102$1122,2008$.

[28] Alani, A.M., Faramarzi, A., Mahmoodian, M. \& Tee, K.F., Prediction of sulphide build-up in filled sewer pipes, Environmental Technology, 35(14), pp. 1721-1728, 2014.

[29] Watkins, R.K. \& Anderson, L.R., Structural mechanics of buried pipes, CRC press, LLC, Washington DC, United States, 2000.

[30] BS EN 1295: 1 - 1997, Structural design of buried pipelines under various conditions of loading - general requirements, British Standard Institution, United Kingdom, 2010.

[31] Gabriel, L.H., Corrugated polyethylene pipe design manual and installation guide, Plastic pipe institute, Irving, Texas, United States, 2011.

[32] Tee, K.F., Khan, L.R. \& Chen, H.P., Probabilistic failure analysis of underground flexible pipes, Structural Engineering and Mechanics, 47(2), pp. 167-183, 2013.

[33] Tee, K.F., Khan, L.R. \& Li, H., Application of subset simulation in reliability estimation of underground pipelines, Reliability Engineering and System Safety, 130, pp. 125-131, 2014.

[34] Mohr, W., Strain based design of pipelines, Department of Interior, Minerals Management Service and Department of Transportation, Research and Special Programs Administration, project No. 45892GTH, USA, 2003. 